18 Press $M$, Tamborlane WV, Sherwin RS. Importance of raised growth hormone levels in the metabolic derangement of diabetes. $N$ Engl $f$ Med 1984;310: $810-5$.

19 Hyer SL, Sharp PS, Brooks RA, Burrin JM, Kohner EM. Serum IGF-1 19 Hyer SL, Sharp PS, Brooks RA, Burrin JM, Kohner EM.

concentation in diabetic retinopathy, Diabetic Med 1988;5:356-60. O Sharp PS, Fallon TJ, Brazier OJ, Sandler L, Joplin GF, Kohner EM. Long term follow up of patients who underwent yttrium-90 pituitary implantation for treatment of proliferative retinopathy. Diabetologia 1987;33:199-207.

21 Diabetic Retinopathy Study Research Group. Preliminary report on effects of photocoagulation therapy. Am f Ophthalmol 1976;81:383-97.

22 Sullivan PM, Caldwell G, Alexandra N, Kohner EM. Long term outcome after photocoagulation for preproliferative diabetic retinopathy. Diabetic $\mathrm{Med}$ 1990;7:788-94.

23 Davies EG, Petty RG, Kohner EM. Long term effectiveness of photocoagulation for diabetic retinopathy. Eye 1989;3:764-7.

24 British Multicentre Study Group. Photocoagulation for diabetic maculopathy: randomised controlled clinical trial using the xenon arc. Diabetes 1983;32:1010-6.

25 Early Treatment of Diabetic Retinopathy Study. Photocoagulation for diabetic macular disease: report I. Arch Ophthalmol Vis Sci 1985;103:1798-806.
26 Early Treatment of Diabetic Retinopathy Study. Photocoagulation for diabetic macular oedema: report IV. Int Ophthalmol Clin 1987;27:265-72.

27 Job D, Eschwege E, Guyot-Argenton C, Anbrey JA, Tchobrutshy G. Effect of , Eschwege E, Guyot-Argenton C, Anbrey JA, Tchobrutsky G. Effect of multiple daily insulin

Diabetes 1976;25:463-9. 28 Kroc Collaborative Study Group. Blood glucose control and the
diabetic retinopathy and albuminuria. N Engl f Med 1984;311:365-72.

29 Brinchmann-Hansen O, Dahl-Jorgensen K, Hanssen KF, Sanduik L. The response of diabetic retinopathy to 41 months of multiple insulin injections, insulin pumps and conventional insulin therapy. Arch Ophthalmol 1988;106: $1242-6$.

30 Reichard P, Bengt-Yngue N, Rosenqulet U. The effect of long term intensified insulin treatment on the development of microvascular complications of diabetes mellitus. $N$ Engl F Med 1993;329:30\%+9.

31 United Kingdom Prospective Diabetes Study. Study design and progress and performance. Diabetologia 1991;34:877-90. *

32 WHO/IDF Europe. Diabetes and research in Europe: the St Vincent declaration. Diabetic Med 1990;7:360.

33 Kohner EM, Porta M. Screening for diabetic retinopathy in Europe: a field guide book. Milan: Boerringer Mannheim, 1992.

\title{
Fully informed consent can be needlessly cruel
}

\author{
Jeffrey S Tobias, Robert L Souhami
}

The past 20 years have seen a welcome change from the traditional paternalist view of the patient as passive recipient of medical advice. This development results from the increasing range of treatment options now available, the wider discussion of these choices both within the profession and more publicly by the media. Patients now wish to participate in decisions about their clinical management to a far greater degree than formerly.

At the same time clinical choices have become increasingly underpinned by reliable outcome data, chiefly as a result of randomised clinical trials, which are now accepted as the best method of determining the relative benefits of competing treatments. ${ }^{1}$ Such trials have been highly influential in changing the clinical management of common conditions both in the United Kingdom and elsewhere. ${ }^{23}$ In our own specialty of cancer medicine, new approaches in chemoprophylaxis and in screening, novel chemotherapy techniques, unconventional radiotherapy fractionation, and so on can be rigorously evaluated only by randomised clinical trials. Though expensive, time consuming, and labour intensive, these trials are fully justified by the considerable human and financial implications of erroneously introducing a doubtfully effective remedy. They are also essential for providing quantitative evaluation of the degree of benefit obtained with a successful new treatment.

Many investigators have found that the practical and ethical problems of conducting randomised clinical trials greatly inhibit their incorporation into clinical practice. As an extreme position, some oncologists have even argued that such trials will have to be replaced by other methods of evaluation, ${ }^{4}$ but no methods have yet been developed that would eliminate the possibility of moderate biases which might distort the results of a new treatment capable of producing a small but important survival difference. To undermine the use of randomised clinical trials when no alternative has been found is unhelpful. Good medical care for the individual patient should be entirely compatible with enthusiastic recruitment into randomised trials. We must not label randomised clinical trials as unethical just because they are difficult to perform.

\section{Practical difficulty of informed consent}

One of the most important ethical and practical difficulties in randomised clinical trials concerns the nature of informed consent. Every patient has the right to be treated in the best possible way for his or her condition and to be as well informed as he or she wishes about the possible approaches available. On the other hand there is the urgent need to validate new treatments. The conflict that may arise between these positions has resulted in many cancer physicians feeling (and expressing) considerable anxiety about the constraining effects of the informed consent procedure as an essential prelude to a patient's participation in clinical trials, particularly randomised clinical trials. ${ }^{5}$

The issue of informed consent has thus become a major barrier to the successful conduct of randomised clinical trials in cancer. The many practical difficulties have led to low levels of recruitment, especially where there is a substantial difference between the treatment policies being compared. In our judgment the medical profession has been unnecessarily defensive and, by and large, has failed to point out that the ethical positions which have been generally accepted are themselves contradictory and impractical. In our view, attempts to gain the "informed" participation of patients in randomised clinical trials are already doing harm in many individual cases.

Most clinicians recognise that the anxious patient sitting opposite them in the consulting room requires, above all, reassurance and a clear exposition of what needs to be done to provide a cure. An increasing degree of frankness on the part of the doctor, for the most part laudible and constructive, may cause considerable anxiety in those patients who would prefer to be directed rather than to participate as an equal partner. It might surprise many to know that this group of patients may include highly sophisticated professionals, ${ }^{6}$ for instance the late Dr Franz Ingelfinger, for many years the editor of the New England fournal of Medicine until shortly before his death from cancer. Having been diagnosed as suffering from a potentially terminal illness, he wrote:

"I received from physician friends throughout the country a barrage of well-intentioned but contradictory advice ... as a result not only I but my wife, my son, and daughter in law (all doctors), and other family members became increasingly confused and emotionally distraught. Finally when the pangs of indecision had become nearly intolerable, one wise physician friend said "what you need is a doctor." He was telling me to forget the information I already had and the information I was receiving from many quarters, and to seek instead a person who would tell me what to do, who would in a paternalistic manner assume responsibility for my care. When this excellent advice was followed, my family and I sensed immediate and immense relief. The incapacity of enervating worry was dispelled, and I could return to my usual anxieties such as deciding on the fate of manuscripts."

Dr Tobias. 


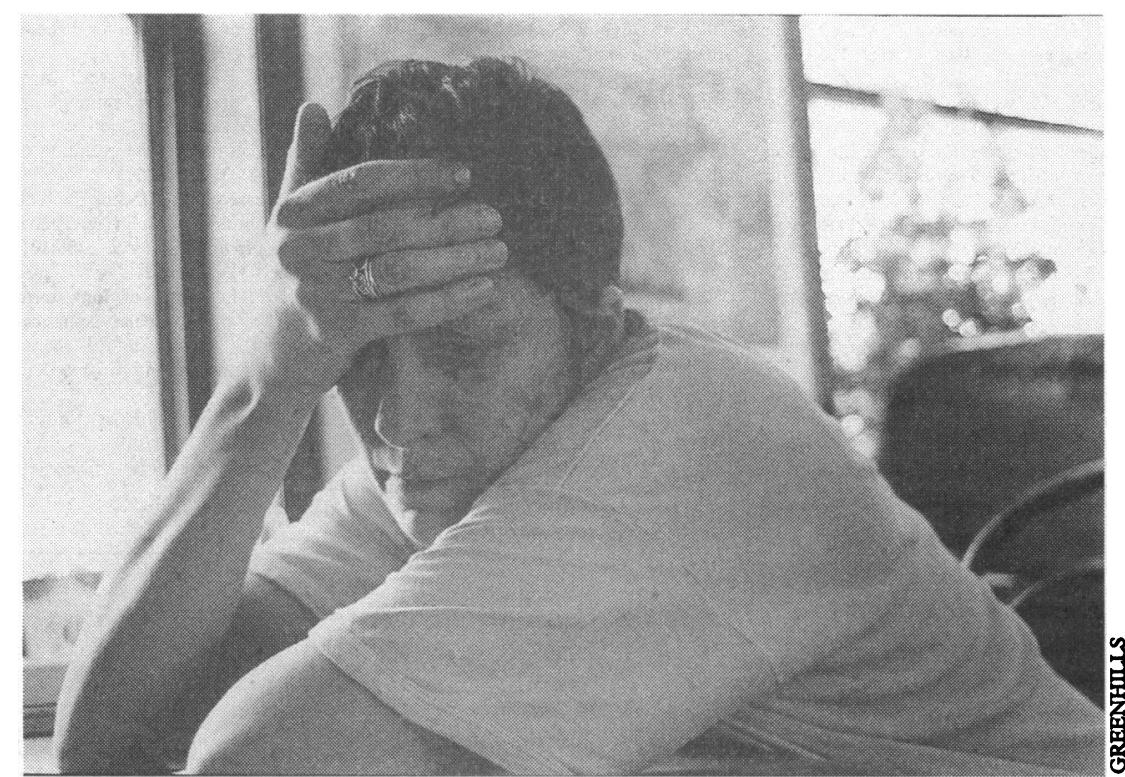

A distraught patient, possibly within days of diagnosis of a potentially lethal illness, may be unable to take in any but the most basic details

\section{Cruelty to patients}

After many years of experience as committed trialists and believers in the statistical and clinical value of the randomised clinical trial, we feel that uniform recommendation for full written informed consent, as outlined for example by the Royal College of Physicians, ${ }^{7}$ may be not only bad for clinical trials but, far more important, unnecessarily cruel to patients.

Consider for example the case of cancer of the cervix. Since we now have, for the first time, several cytotoxic agents with activity in patients with advanced disease, it is of critical importance to establish whether or not this new approach, combined with the conventional treatment (radiotherapy), offers an improvement in overall cure rate. If it does, this would be the first step forward in this tumour since radiotherapy was introduced as standard treatment over 50 years ago. The issue can be settled only by clinical trials of sufficient size to quantify any possible benefit, but the difficulty that many trialists have with the informed consent consultation with these patients has made this kind of study extremely problematic.

It is neither faintheartedness nor a disinclination to be questioned that discourages the clinician; rather, it is the overwhelming difficulty of describing the details of a potentially valuable (but as yet unproved) new remedy, gaining the patient's assent, and later having to inform her that she has been randomised to receive radiotherapy alone. However carefully the pros and cons of chemotherapy may have been explained, the result of the randomisation often leads the doctor towards a rather shabby display of back pedalling, in which the possible advantages of the chemotherapy are "talked down" and perhaps the side effects "talked up." The patient may become extremely distressed, which is not only counterproductive (with refusal to participate) but also alarming for the doctor and by no means easily resolved.

It does not take many such consultations to change a well intentioned and committed trialist into a disgruntled clinician who no longer feels that the game is worth the candle. It can be extremely difficult to sustain the doctor-patient relationship through such a harrowing discussion, and particularly unfortunate for patients such as those in the example above whose treatment by radiotherapy (that is, the control group) would be regarded as entirely conventional and proper. Both the support and reassurance of the doctor, and the patient's trust and confidence in the medical advice, may have been irretrievably lost. Too frank an explanation, with patient overload from too much information, can have most serious consequences. ${ }^{8}$

\section{A way forward}

The ethical double standard is obvious. If doctors are sure they know which is the correct general policy of management, and if they recommend treatment according to their judgment or preference, they are excused any ethical criticism on the grounds of freedom of clinical judgment. All would agree that a clinician must be able to advise according to the particular circumstances (medical, social, psychological) of the patient, but what if the doctor is ill informed or dogmatic? Why should the clinician who shares with expert colleagues a genuine doubt about the best treatment be subject to the difficulties outlined above? He or she may even face being pilloried in the national press. ${ }^{9}$ Recently Segelov et al argued that the decision not to participate in an approved available clinical trial should be subject to the same ethical scrutiny (by institutional committee) as trial entry. ${ }^{10}$ We sympathise with this view, one which would indeed go some way to redress the unfair ethical balance. However, we suggest an alternative approach that recognises the difficulty of the process of informed consent, rather than addressing the general ethical problem of participation in clinical trials which Segelov et al discuss.

In ordinary clinical practice (outside clinical trials) it is essential that doctors judge how quickly to impart information, and to what degree they will spell out the medical facts, especially if they are frightening or unpalatable. The move towards full disclosure of all details of diagnosis, treatment, and prognosis is a major change in social perception in the United Kingdom and the United States-one by no means found in all countries to the same degree. However, no sensible doctor makes full disclosure to every patient. This would be a recipe for needless cruelty and distress. Although in most branches of medicine an honest and candid approach is generally desirable, ${ }^{11}$ one of the challenges of clinical medicine is to know how quickly to proceed and how to judge the amount of information which should be given at a particular moment. Informing a patient is a continuous process.

We suggest that the process of informed consent should be viewed as another straightforward instance in which the clinical judgment of the doctor is paramount. Clearly, for a patient who wishes to know what underlies all aspects of decision making, there is no doubt that a full explanation should be given, together with all the necessary information about the trial. At the other extreme a distraught patient, possibly within days of diagnosis of a potentially lethal illness, may be unable to take in any but the most basic details. Often in desperate need of reassurance, patients such as this can hardly be expected to cope with a full discussion of options to be decided at random. In between there will be more complex judgments in which the outlines of alternative treatments must be explained and the patient reassured that the treatment policy decided on will always be in his or her best interests. The crucial point here may sometimes include the question of whether to disclose that this decision is based on a randomisation in which the physician plays no direct part. This may be very unnerving for patients, and in some situations-for example, in discussion with parents of a child with cancer (in which age group randomised trials are usual) -it may be extremely difficult. Many patients wish to help to advance medical knowledge, and gain comfort and support from feeling that they are doing so, although these same patients may feel disturbed by 
the thought that their doctor is not making the fundamental decision about treatment policy.

We believe that many doctors already vary what they say to patients in just the way we describe. We suggest that they should not be ashamed of so doing-whatever the ethicists say. Just as they know that the ethical imperative always to tell the complete truth in all aspects of clinical practice is wholly impractical, so also is the notion that fully informed consent means an uncompromising discussion of the design and execution of a clinical trial to every patient.

The deliberate use of what Collins et al describe as "humanly inappropriate" written informed consent procedures $^{12}$ led in the ISIS-2 trial (of streptokinase and aspirin in acute myocardial infarction) to a very poor recruitment in the United States (where such consent was deemed essential) compared with the United Kingdom, where consent was obtained in the manner considered best for the individual patient. Collins et al draw attention to the thousands of deaths which may have resulted worldwide from the unnecessary delay in completing the study. Cancer treatments are far more costly, toxic, and prolonged than the treatments in the ISIS-2 trial and a greater degree of discussion will therefore usually be necessary, though the principle involved is just the same. An informed consent procedure must be used which is humane for that individual patient, and not for the study as a whole.

The counter argument will be that we are advocating a paternalistic "doctor knows best" approach. We are not. We wish to see this discussion with the patient informed by the same wisdom, judgment, and kindness which should be part of all aspects of clinical care. We believe that the ethical pressure that has put us so much on the defensive is flawed. It may in part result from fears of a medicolegal nature, many of which have been imported from the United States, where litigation for alleged medical negligence is so much more common. It may be that lawyers and ethicists in the United Kingdom will wish to push us in the same direction, but we should resist them on grounds both of common sense and humanity.

1 Williams CJ, ed. Introducing new treatments for cancer: practical, ethical and legal problems. Chichester: Wiley, 1992.

2 Early Breast Cancer Trialists Collaborative Group. Systemic treatment of early breast cancer by hormonal, cytotoxic or immune therapy. Lancet 1992;339: 1-15, 71-85.

3 GISSI Collaborative Group. Effectiveness of intravenous thrombolytic treatment in acute myocardial infarction. Lancet 1986; i:397-402.

4 Hellman S, Hellman DS. Of mice but not men-problems of the randomized clinical trial. N Engl f Med 1991;324:1585-9.

5 Baum M, Zilkha $K$, Houghton J. Ethics of clinical research: lessons for the future. $B M F$ 1989;299:251-3.

6 Ingelfinger FJ. Arrogance. N Engl f Med 1980;303:1507-11.

7 Royal College of Physicians. Guidelines on the practice of ethics committees in medical research involving human subjects. 2nd ed. London, RCP, 1990.

8 Thornton HM. Breast cancer trials: a patient's viewpoint. Lancet 1992;339: 44-5.

9 Raphael A. How doctor's secret trials abused me. Observer 1988; October 9.

10 Segelov E, Tattersall MHN, Coates AS. Redressing the balance-the ethics of not entering an eligible patient on a randomised clinical trial. Ann Oncol 1992;3:103-5.

11 In cancer, honesty is here to stay [editorial]. Lancet 1980;ii:245.

12 Collins R, Doll R, Peto R. Ethics of clinical trials. In: Williams $C J$, ed. Introducing new treatments of cancer: practical, ethical and legal problems. Chichester: Wiley, 1992:49-65.

(Accepted 1 September 1993)

\section{An uncomfortable surprise}

In that limbo between passing finals and starting my first house job I took a surgical locum post in a north London hospital. I remember feeling a profound ambivalence: the kudos of a newly qualified doctor uncomfortably mixed with a realistic appreciation of my inadequacies. The senior registrar, a brusque, matter of fact individual, recognised my plight, and planned a gentle induction to practical procedures. I was asked to catheterise the man in the corner of the ward.

Drawing back the curtain I saw a young man made old by disease (I believe he had motor neurone disease, but I have never been sure). He was bent double, his body stiff and unyielding as if in rigor mortis. With great difficulty a nurse and I eased him on to his back and attempted to unlock his hips and knees and separate his legs. $\mathrm{He}$ expressed his pain in his eyes-moist, pleading for release. His mute resignation unnerved me more than if he had cried out in pain and protest. The nurse, a kindly middle aged lady, stroked his hand and called him by his first name. His eyes narrowed and I sensed a welling up of indignation at being patronised.

I attempted with great difficulty to remember the sequence of events in the only catheterisation which I had witnessed. Initially all went well. I introduced the tip of the catheter into the urethra and began to push gently. I had decided that the slower I was the less likely the patient was to feel pain.

My sense of tentative control precipitously evaporated when, push as I might, the catheter would advance no further. Confusion gave way to increasing panic. Should I push harder? The nurse had obviously decided that it was nothing to do with her and resumed stroking the patient's hand. I risked looking at him. His eyes were closed, the lids gently flickering. Impotence and guilt overwhelmed me. A desperate last shove was rewarded by a gush of warm urine up my arm and over the bed. This time we exchanged glances of mutual and profound relief. A muffled apology for the time I had taken preceded my dash for the door.

The senior registrar, unaware of the trauma I had endured, said, "Sad case. Brilliant surgeon." I was about to quip that I did not think surgery would be my metier when he added, "He qualified in this hospital-only six or seven years before me." I realised that the senior registrar was talking about my patient. Why was I given the job of catheterising him? Surely it should have been done by a consultant? What must he have thought of my ineptitude? Did he realise that I didn't know he was a doctor?

That evening I shared my sense of betrayal with my wife. Her reaction was sympathetic and supportive, but she asked how I would have done things differently had I known that the patient was a doctor. I confessed I would have done exactly the same. My anger had something to do with hierarchy and status. He was a "brilliant surgeon" and I was a ham fisted tyro. Somehow or other he deserved better.

Over the next few days I thought of little else. I avoided that end of the ward as much as possible, despite the urge to apologise. By the third day my despair had filtered back to the senior registrar. If I had expected a sympathetic hearing I was to be disappointed. "It's quite simple," he said bluntly. "You imply that had you known he was a doctor you'd have acted differently. Isn't everyone entitled to expect the same treatment? Tailoring treatment to the perceived status of a patient is a travesty."

Of course, he was right. It was just as well that I learnt such a lesson early on in my medical career. Many have not.-ROBERT WILKINS is a consultant psychiatrist in Berkshire.

We are delighted to receive submissions of up to 600 words on $A$ paper (or patient or book) that changed my practice, $A$ memorable patient, The one message I would like to leave behind, or related topics. 